\title{
Trafficking of Immune Cells in the Cornea and Ocular Surface
}

\author{
Yureeda Qazi, \\ Aslihan Turhan and Pedram Hamrah \\ Cornea Service, Massachusetts Eye and Ear Infirmary, \\ Department of Ophthalmology, Harvard Medical School \\ USA
}

\section{Introduction}

The role of immuno-inflammatory responses in the cornea and ocular surface has continuously been evolving over the past decades and has been becoming the center stage for therapeutic approaches for many diseases. In fact, the relevance of inflammation as a significant component in the pathophysiology of most acute and chronic forms of corneal and ocular surface diseases (e.g., microbial keratitis, allergy, and dry eye syndrome) has become evident. Both local and systemic immunomodulation with anti-inflammatory agents have been used successfully in improving these conditions or bringing these conditions under control. Thus, understanding the cellular and molecular mechanisms by which the ocular surface participates in immuno-inflammatory disorders is crucial for a more rational clinical approach to treating these diseases.

There are several unique anatomical and physiological features of the cornea and ocular surface as compared to other tissues in the body, which translate into specific mechanisms by which they are involved in both inciting and expressing immunity, as well as preventing unnecessary inflammation. There are a very large number of immune and inflammatory disorders that involve the cornea and ocular surface. Control of leukocyte entry and migration within the cornea and ocular surface is thus vital to regulate protective and pathological responses. While local control of pathogens is dependent on the ability of immune cells to access and operate within these sites, too much inflammation can be deleterious and lead to loss of vision. In this chapter, the current knowledge on the coordinated migratory events that regulate leukocyte trafficking in the cornea and ocular surface are discussed. The aim is to first provide an overview of the contribution of resident bone marrow (BM)-derived cells of the cornea and ocular surface. Second, the role of infiltrating leucocytes in some of the innate defense mechanisms will be discussed. Third, we will provide a summary of the mechanisms that dictate immune cell trafficking to the cornea and ocular surface in response to inflammation. Finally, we will discuss trafficking mechanisms of antigen presenting cells from the cornea and ocular surface to draining lymph nodes where the immune responses are initiated. 


\section{Role of leukocytes in disease}

\subsection{Overview of resident leukocytes}

The cornea and ocular surface have constant and direct contact with the external world. This necessitates a powerful and intrinsic immune surveillance system involved in their natural defense. Resident ocular tissue elements together with circulating bone marrow-derived cells are important components of this system, delicately balancing defense and tolerance under steady sate conditions. The ocular surface consists of three distinct anatomical regions: the cornea, limbus, and the conjunctiva. These regions function both in concert and independently against microbial, immunogenic and traumatic insults.

Antigen presenting cells (APCs) and in particular dendritic cells (DCs) orchestrate the immune response through their capacity to capture, process and subsequently present antigens. APCs serve as the principal immune sentinels to the foreign world. They can be divided into 'professional' and 'nonprofessional' types. While the latter are found among nonlymphoid tissues (e.g., vascular endothelial or some tissue epithelial cells), professional APC are BM-derived, and form an integral part of the immune system. Professional APCs include DCs (including epithelial Langerhans cells; LCs), macrophages, and B cells, although DCs are the most potent APCs. Expression of major histocompatibility class II (MHC-II) antigens on DCs, whose primary function is to distinguish between self and nonself, plays an integral role in antigen recognition and presentation. DCs have a dual function as key regulators of $\mathrm{T}$ cell immunity and tolerance induction to both self and foreign antigens. Precursor and progenitor DCs constitutively repopulate normal tissues from the bloodstream, and are recruited in elevated numbers to sites of inflammation. A second type of DC precursors is constituted by peripheral blood monocytes that are recruited during an inflammation.

DCs originate from bone marrow hematopoietic stem cells. (Traver et al., 2000; Wu et al., 2001) DC progenitors are not restricted to the BM and can be found in multiple locations. These progenitors can differentiate into DC upon challenge in peripheral tissues. Fully differentiated DC are found in healthy tissues as immunologically immature cells, being able to sample foreign antigens, but not able activate T cells. Although rare in numbers in the circulation, one fully mature DC is capable to interact with ten thousand $T$ cells per day.(O'Keeffe et al., 2003) DC consist of several distinct populations that can be differentiated by surface and intracellular phenotypic markers, immunological function, and anatomic location. Irrespective of their phenotype and immunological role, DC exert their activity in the eye remote from their place of origin, where they utilize their advanced migratory skills for navigation. Currently, factors leading to the development from precursor DC to differentiated mature DC are still largely unknown. It has been shown that depending on the environmental cues, different forms of DC may be generated.(Naik et al., 2006) Further, while in lymphoid as well as in some non-lymphoid organs,(Kabashima et al., 2005; Merad et al., 2002) DC have been shown to proliferate locally, it is yet unclear whether resident corneal DC have the same proliferative potential, or are alternatively replenished through circulating DC. The diverse functions of DC in immune regulation depend on the diversity of DC subsets and lineages and on the functional plasticity of DCs at their immature stage. 
Over the last several decades, the search for corneal APC, largely reliant on their presumed and universal MHC-II expression, had led to the dogma that APC are essentially absent in the central corneal. This absence of corneal APC was assumed to be a critical component of corneal immune privilege. However, this paradigm has now shifted with the demonstration of a diverse population of resident APC over the last years.(Hamrah et al., 2003a; Hamrah et al., 2003b, c) Dendritic cells, the sentinels of the immune system, were recently discovered to reside not only in the peripheral cornea, but also in the centreal cornea (Fig 1).(Hamrah et al., 2003c; Hamrah et al., 2002b; Liu et al., 2002) While a large number of DC are MHC class $\mathrm{II}^{+}$in the periphery, a large population of MHC class II-negative immature/precursor DC are present both in the central epithelium and stroma.(Hamrah et al., 2003c; Hamrah et al., 2002b) Immature DC do neither express major histocompatibility complex (MHC)-II nor costimulatory molecules unless they are incited by cytokines. Thus, in contrast to other organs, where terminally differentiated populations of resident DC and/or macrophages outnumber colonizing precursors, large numbers of DCs within the cornea remain in an undifferentiated state.

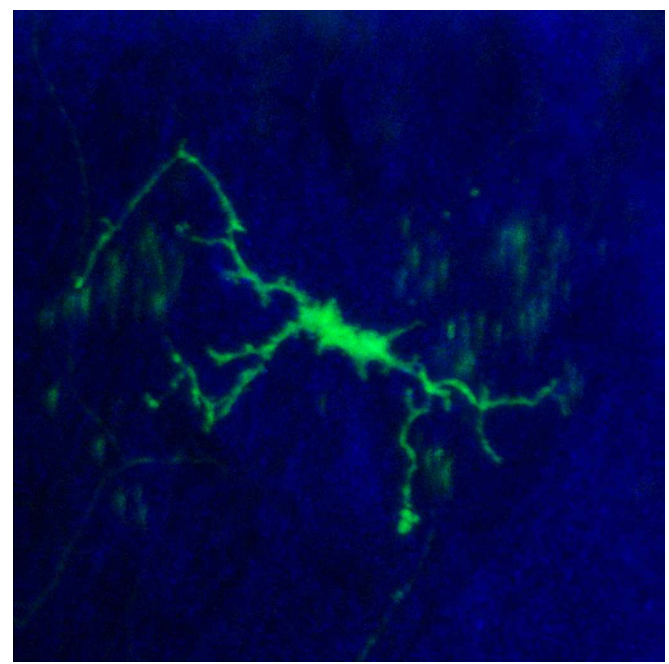

Fig. 1. Dendritic Cell in central corneal epithelium in CD11c-Yellow fluorescent protein (YFP) transgenic mouse

The constitutive presence of these DCs in the cornea focuses now attention on the cornea as a participant in immune and inflammatory responses, rather than the cornea being essentially a collagenous tissue that simply responds to the activity of infiltrating cells. Other immune cells that populate the cornea and ocular surface are T cells, B cells, macrophages, plasma cells, and neutrophils (PMN). Further, macrophages and neutrophils together with natural killer (NK) cells, initially constitute the primary innate immune response, while DCs, T cells and B cells largely play a role in the secondary, adaptive response.(Janeway C, 2004) While the primary innate immune response is non-specific, rapid, and lacks memory, the secondary adaptive immune response is slower, but highly specific. Further, $\mathrm{T}$ and $\mathrm{B}$ cell responses maintain immunological memory, such that any following encounters with the same antigen will lead to rapid and robust immune responses. 


\subsection{Microbial keratitis}

\subsubsection{Herpes simplex virus type-1 (HSV-1)}

HSV-1, is a member of the $\alpha$-herpesviridae family of double-stranded DNA (dsDNA) viruses.(Shukla \& Spear, 2001) HSV-1 infections are prevalent both in the developed and developing countries with a higher and earlier onset of seroconversion in population groups of lower socioeconomic status.(Whitley \& Roizman, 2001) $60 \%$ to $90 \%$ of the global adult population is infected with this pathogen, with a remarkably high prevalence of approximately $90 \%$ in the United States.(Carr et al., 2001; Whitley \& Roizman, 2001) The two main forms of ocular HSV-1 infections are epithelial keratitis, and immune stromal keratitis.(Thomas, J. \& Rouse, 1997) In the West, HSV-1 is also the leading cause of blindness secondary to recurrent infection, corneal stromal inflammation (herpes stromal keratitis; HSK), stromal thinning, neovascularisation and scarring.(Dana, M. R. et al., 2000)

The ocular surface, through several means, is able retard host invasion by external pathogens. The tear film which forms the outermost layer of the ocular surface presents the first barrier to viral invasion.(Farris, 1998) Some of the anti-viral factors in the tear film include, but are not limited to, tear film proteins such as lysozyme, immunoglobulin A (IgA), lactate dehydrogenase (LDH), complement proteins, amylase, peroxidase, as well as interferons alpha (IFN $\alpha$ ) and beta (IFN $\beta$ ). (Babu et al., 1995; Chatterjee et al., 1984; Chen et al., 1994) Since herpes viruses rely on replication and dissemination in metabolically active cells (Schang et al., 1998; Schang et al., 2000), the terminally differentiated outer layers of the corneal epithelium act as both a physical and metabolic barrier against viral entry. In the event of a breach in the integrity of the corneal epithelium, the virion attaches to epithelial cells via interaction of its surface glycoproteins with cognate receptors, (Campadelli-Fiume et al., 2007; Shukla et al., 1999; Spear, 2004) leading to either attachment, surfing and fusion of the virion envelope to the host cell plasma membrane, or, via endocytosis of the nucleocapsid into the host cell cytoplasm. Having intercepted the barriers to entry, HSV-1 inhibits its host's programmed cell death, assembles its immune-defying, host-crippling machinery to invade, replicate and infect the cornea, nerves and eventually the trigeminal ganglion where the virus maintains lifelong latency, leading to recurrent infections and potentially irreversible damage to the corneal tissue.(Akhtar \& Shukla, 2009; Whitley \& Roizman, 2001) Transmission may occur through cell lysis and shedding of viral progeny or cell-to-cell spread of the virion. Once the host corneal epithelial layers are penetrated, HSV replicates in the corneal epithelial cells. Following host infection, the outcome of viral latency or resolution has been shown to be dependent on the initial viral load.(Kintner \& Brandt, 1995).

Cytokines are low molecular weight proteins produced by various resident corneal cells such as epithelial cells, stromal cells, and APCs.(Torres \& Kijlstra, 2001) They are responsible for recruiting inflammatory and immune cells via cell-to-cell signalling through autocrine, paracrine and endocrine pathways, thus promoting tissue damage.(Balkwill \& Burke, 1989) As the disease course changes, expression profiles of cytokines follow suit. During the early phase of HSK, the cornea expresses interleukin (IL)-1a, interferon (IFN)- $\gamma$ and IL-2, whereas IL-4 is expressed later, indicating that the Th1 T cell response is required for induction of HSK. (Babu et al., 1995; Niemialtowski \& Rouse, 1992b) (Heiligenhaus et al., 1999) While IL-2 may be responsible for incurring destructive effects on the stroma, IL-2 knockout mice 
are more prone to severe HSV infection, which is ameliorated by providing recombinant IL2 treatment, hence indicating that the Th1 T cell response not only plays a role in tissue destruction, but also plays a protective role against HSV-1 invasion.(Ghiasi et al., 1999) Paradoxically, IFN- $\gamma$ has also been implicated in the clearance of virus from the cells thus reducing latency, (Bouley et al., 1995; Smith et al., 1994) (Hendricks et al., 1991) yet driving immunopathogenesis as exemplified by the reduction in HSK severity following neutralisation of IFN- $\gamma$ titres beforehand. (Hendricks et al., 1992b; Niemialtowski \& Rouse, 1992a, b) Among the array of cytokines produced, IL-1 is particularly pertinent to corneal melting by induction of LC migration into the cornea thereby priming the tissue for further destruction. In order to combat the effects of IL-1, human corneal epithelium and stroma constitutively express interleukin-1 receptor antagonist (IL-1 RA), which helps maintain corneal immune privilege.(Dana, M. R. et al., 1998; Kennedy et al., 1995) Finally, while proinflammatory cytokines contribute to the augmentation of the immune response, vascular endothelial growth factor (VEGF) secreted by polymorphonuclear (PMN) cells, and local epithelial cells, contributes to corneal neovascularization in HSK.(Lee, S. et al., 2002; Zheng, M. et al., 2001)

Chemokines are specific, small cytokines of 8-10 kDa and can be classified according to their structure and function. Structurally, they fall into four families, the two most important of which are the CXC (alpha) and CC (beta) families. The CC and CXC chemokines are named based on intervening residues between their amino $(\mathrm{N})$-terminal cysteine amino acids. Hence, the CC family of chemokines have two adjacent cysteine amino acids near the Nterminus without an intervening residue. However, in the CXC family of chemokines, these $\mathrm{N}$-terminal cysteine residues are separated by an amino acid " $\mathrm{X}$ ", thus their " $\mathrm{CXC}$ " salutation. Chemokine receptors (CCR) CCR1, CCR2, CCR5, CXC chemokine receptor (CXCR) CXCR2 and their ligands (CCL/CXCL) have a well-defined role in HSV. Viral replication leads to expression of chemokines such as macrophage inflammatory protein (MIP)-1 $\alpha / C C L 3$, KC/CXCL1, MIP-1 $\beta / C C L 4$, MIP-2/CXCL2, monocyte chemotactic protein (MCP)-1/CCL2 and lymphotactin/XCL1. (Thomas, J. et al., 1998) (Wolpe et al., 1989) Of these, MIP-1 $\alpha$ /CCL3 plays the most pivotal role in causing stromal inflammation, possibly by recruiting neutrophils and $\mathrm{T}$ cells as seen in experimental studies on murine corneas.(Tumpey et al., 1998; Wolpe et al., 1988) Furthermore, CXCR3 and its ligands, namely, monokine induced by gamma interferon (MIG)/CXCL9, interferon gamma-induced protein 10 (IP-10)/CXCL10 and interferon-inducible T-cell alpha chemoattractant (I-TAC)/ CXCL11 may also contribute to the development of a protective, anti-viral immune response seen in the cornea following HSV-1 infection. (Carr et al., 2008; Wuest \& Carr, 2008) These chemokines may form potential targets for therapy in HSK.

It is well established that primary infection with HSV-1 incites both a localized innate immune response, and systemic immunity through the adaptive arm of the immune cascade. The localized innate immune response involves PMNs, natural killer (NK) cells, and macrophages, with the adaptive immune response involving DCs and T cells.(Brandt \& Salkowski, 1992; Ghiasi et al., 2000; Hendricks \& Tumpey, 1990; Meyers-Elliott \& Chitjian, 1981; Niemialtowski \& Rouse, 1992a; Pepose, 1991; Tullo et al., 1983; Tumpey et al., 1996) Clinically, the collection of these cells is seen as infiltrates in the corneal stroma. Within 48 hours following infection, PMN cells, which constitute the first line of defense, are recruited to the cornea by means of the limbus vasculature, following a multi-step adhesion cascade, 
including selectins, integrins, and chemokines.(Thomas, J. et al., 1997) A cytokine and chemokine response by recruited PMN cells, including tumor necrosis factor (TNF$\alpha$ ),(Daheshia et al., 1998) then quickly translates into recruitment of other cells to the site of infection. Additionally, toll-like receptors (TLRs) expressed on the corneal epithelium and stroma, recognise pathogens and their activation leads to generation of both an innate and acquired adaptive immune responses. Of particular note are TLRs 3, 4, 7, and 9 which mediate an anti-viral response to corneal epithelial infection with HSV-1 (Redfern \& McDermott) Binding of the pathogen to TLRs causes release of cytokines and chemokines which provide alert signals to draw in inflammatory cells such as neutrophils and lymphocytes. TLR activation also induces resident corneal APCs to express MHC-II and costimulatory molecules thus engaging the acquired immune response.(Hamrah \& Dana, 2007) The anti-viral immune response of TLR7 has been successfully tested in clinical trials treating HSV following the success of Imiquimod, an FDA-approved TLR7 agonist used in the treatment of infection with the human papilloma virus (HPV).(Miller, R. L. et al., 2008) Despite encouraging results of TLR agonist therapy for HSV, one must exercise caution in their use since excessive TLR stimulation can lead to an unfavourably strong immune response with much damage to bystander cells and tissues of the eye.

Langerhans cells have been found in abundance near the limbus and are recruited to the site of inflammation within a few days in the wake of HSV-1 infection.(Streilein et al., 1979) (Asbell \& Kamenar, 1987; Hendricks et al., 1992a) There they process the viral antigens for presentation to naïve T-helper (Th0) cells in draining lymph nodes. These Th0 cells mature into Th1 or Th2 cells depending upon the type of cytokines, prostaglandins and costimulatory molecules released by LCs and cells of the innate immune system.(Torres \& Kijlstra, 2001) The extent of stromal damage in HSK is affected by the density of LCs in the cornea.(Asbell \& Kamenar, 1987; Hendricks et al., 1992a; Jager et al., 1991; Jager et al., 1992; Miller, J. K. et al., 1993) Virally-induced migration or maturation of LCs in the cornea precedes the development of HSK. Induction of LC migration into the central cornea before HSV-1 infection results in an accelerated and enhanced delayed type hypersensitivity (DTH) response to HSV-1 antigens, and an increased severity of HSK. On the contrary, depletion of DCs reduces the incidence and severity of HSK, suggesting a role for DCs in the induction of a T cell response. These findings have led to the conclusion that HSV-1 infection results in de novo migration of LCs from the limbus, which in turn might play a role in the immunopathology of HSK through presentation of antigens to T cells in the infected cornea. Thus, patients that have a higher density of corneal LCs are likely to get more severe forms of HSK, which highlights the role of LCs as a potential therapeutic target in HSK.

HSK has been studied extensively using mouse models of disease and CD4+ T helper 1 (Th1) cells have been purported to be key mediators in the immunopathogenesis of corneal HSV-1 infection. (Hendricks, 1997; Streilein et al., 1997) In mice depleted of CD4+ cells, HSK development and progression was prevented or retarded, whereas depletion of CD8+ cells either made no difference or made the severity of HSK worse. (Newell et al., 1989a; Newell et al., 1989b) Corticosteroids, which are commonly prescribed in addition to antiviral therapy in HSK, work partially via inhibition of CD4+ T-cell response and are thus effective in controlling inflammatory damage to the eye. Among other local tissue factors, the kind of T-helper response generated is orchestrated by a fine balance between cytokines IL-12 and IFN- $\alpha$, and IL-4 and IL-10, which mature Th0 cells into Th1 or Th2 respectively. (Torres \& 
Kijlstra, 2001) The predominant expression of cytokines IL-2 and IFN- $\alpha$ in HSK further corroborates the role of CD4+ Th1 immune response in HSK pathogenesis.(Hendricks et al., 1992b; Niemialtowski \& Rouse, 1992b) The role of Th2 cells in HSK is far more controversial and inconclusive. While some groups state that Th2 cells have negligible involvement in HSK, (Niemialtowski \& Rouse, 1992a, b) others either ascribe Th2 cells as inducers of HSK, (Foster et al., 1993; Jayaraman et al., 1993) or ascribe their role to convalescent phase of HSK.(Jayaraman et al., 1993) There is however one caveat; the kind of response generated is also driven by the strain of HSV-1. Corneal infections with the reticuloendotheliosis (RE) strain of HSV-1 are predominantly CD4+ driven, whereas the relatively less neuroinvasive (KOS) strain recruits and activates CD8+ T cells. (Hendricks \& Tumpey, 1990; Newell et al., 1989a; Russell et al., 1984) T cell mediated delayed type hypersensitivity eventually is critical for the elimination of the virus. After this point circulating memory $\mathrm{T}$ and B lymphocytes continuously scan the cornea.

The suggested T-cell mediated immune response in HSK, is supported by the fact that specific HSV epitopes have been shown to mount an immune response by generation of autoreactive T cells. (Zhao et al., 1998) Murine studies of chronic HSK further demonstrated that despite clinical signs of active disease and lesions, 10-15 days post viral inoculation, viral antigens and messenger RNA (mRNA) were undetectable in the corneas of these mice.(Babu et al., 1996) Furthermore, Avery and colleagues performed elegant experiments, demonstrating that transfer of autoreactive $\mathrm{CD} 4^{+} \mathrm{T}$ cells to into athymic mice infected with HSV-1, results in the development of HSK.(Avery et al., 1995) However, there is ongoing debate regarding the source of antigenic response elicited in HSK. Verjans et al. have shown that $\mathrm{T}$ cells harvested and cultured from HSK donor corneas failed to show reactivity against human corneal antigens.(Verjans et al., 2000) Moreover, human studies to date have been inconclusive and it has been hypothesised that a variable clinical spectrum of disease in patients with recurrent HSK may either be due to a heterogeneous immune response to the HSV epitopes, or, to heterogeneity in the expression of corneal autoantigens in the host.(Ellison et al., 2003)

Based on the ability of HSV-1 to circumvent the immune response and maintain latency, along with the complexity of immune players that orchestrate signalling cascades leading to a spectrum of disease seen clinically, it is challenging for clinicians to treat HSK effectively. Attempts towards immunomodulation of HSK have been made, ranging from induction of apoptosis in T cells by amniotic membrane transfer,(Bauer et al., 2009) to suppression of chemotaxis and activation of CD4+T cells by targeting chemokine receptors.(Komatsu et al., 2008; Lee, S. K. et al., 2008). However, with an evolving and deeper understanding of the molecular mediators of HSV-1 infection, new molecular targets may provide platforms for emerging therapies.

\subsubsection{Pseudomonas keratitis}

One of the most important organisms in the group of bacterial keratitides is the Gramnegative bacterium Pseudomonas aeruginosa. P. aeruginosa is an opportunistic pathogen, which like other microbes, requires a breach in the corneal surface for infection.(Hazlett et al., 1978) Such infections are typically seen in individuals who wear contact lenses for extended periods of time, and in nosocomial or tropical settings stemming from the ability of the bacterium to grow in any niche without much nutritional support.(Hazlett, 2004) 
Pseudomonal keratitis is highly invasive and can lead to corneal perforation within 24-48 hours post-infection.(Jones, 1973) Pseudomonal infections of the cornea are marked by inflammation and necrosis; there is a suppurative stromal infiltrate, coagulative necrosis, epithelial edema, a mucopurulent exudate, and in some cases a paracentral corneal ring infiltrate that can be seen in addition to a hypopyon.(Hazlett, 2004) One of the main host factors that is the culprit for a stromal meltdown is the massive recruitment of neutrophils, which release lysosomal enzymes and oxidative compounds, digesting collagen of the stromal extracellular matrix. (Carubelli et al., 1990; Nicas \& Iglewski, 1985; Trinkaus-Randall et al., 1991; Van Horn et al., 1978; Weiss, 1989) IL-6, one of the cytokines expressed within 24 hours of P.aeruginosa invasion, may be involved in recruitment of PMNs to the site of inflammation by upregulating the expression intercellular adhesion molecule-1 (ICAM-1), a key molecule involved in migration of neutrophils.(Cole et al., 1999; Youker et al., 1992) Integrin-mediated neutrophil migration is a critical phenomenon that occurs not only within the proteoglycan matrix, but also among stromal keratocytes which express adhesion molecules.(Burns et al., 2005)

The rapid spread of infection in the early stages of disease has been attributed in part to a delayed response from the responsible TLRs, TLR-2, -4 and -5 , which are expressed at a later stage in the disease thus leading to a delay in activation of both the innate and adaptive arms of the immune response. (Jin et al.) Using a murine model of pseudomonal keratitis, Sun and colleagues demonstrated that P.aeruginosa activates expression of TLR-4/5 on resident corneal bone marrow-derived macrophages, inducing transcription of chemokines and cytokines such as KC/CXCL1, as well as IL-1 $\alpha$ and IL-1 $\beta$. Subsequent recruitment of neutrophils into the corneal stroma leads to destruction of P.aeruginosa. The produced IL-1 has a positive feedback effect by activating the IL-1 receptor in macrophages and other cells of the cornea, thus ensuring a sustained response against the bacteria.(Sun et al.) While a sustained immune response favours reducing bacterial load, it is also associated with bystander local tissue damage from dysregulation of cytokines and chemokines as seen by elevated expression of TNF- $\alpha$, MIP-2/CXCL2, IL-1 $\alpha$ but low levels of IL-10.(Zhou et al.) It is evident that the role of a prompt and efficient immune response is critical in curtailing the spread and severity of pseudomonal keratitis, and eventually in preventing loss of vision. However, the caveat to a robust immune response remains the collateral damage incurred to surrounding cells and tissues.

From a therapeutic standpoint, TLRs make interesting molecular targets. Particularly, TLR-9 is one of the first in its class to be expressed when the cornea is invaded by P. aeruginosa. Huang and colleagues used RNA interference (RNAi) to knockdown TLR-9 in mice which resulted in decreased corneal opacity, fewer corneal perforations, with decreases in PMNs, inductors of the Th1 pathway IFN- $\gamma$ and IL-12, and mediators of chemotaxis IL-1 $\beta$ and MIP-2/CXCL2, but higher bacterial titers than controls.(Huang et al., 2005) Further, when mice were either depleted of $\mathrm{CD}^{+} \mathrm{T}$ cells or received IFN- $\gamma$ neutralising antibodies prior to inoculation, they were spared corneal perforation and had a reduced DTH response, corroborating the role of a CD4+ T-cell mediated immunopathogenesis of this disease.(Kwon \& Hazlett, 1997) Cytokines released by CD4+ T cell and LC result in infiltration of higher numbers of PMN, eventually leading to increased corneal.(Hazlett et al., 2001; Hazlett et al., 2002) While some propose that in order to minimise this collateral damage to ocular tissues, therapies should consider directing the immune response from 
CD4+/Th1 mediated towards a Th2 pathway, (Kijlstra, 1994) others are of the opinion that it is the balance between pro-and anti-inflammatory mediators that is of greater significance in pseudomonal keratitis. (Hazlett, 2004) (O'Callaghan et al., 1996)

\subsubsection{Fungal keratitis}

Fungal keratitis is a vision-threatening infection and has seen a recent continual rise in incidence, with a spike during 2005-2006, following Fusarium contamination of a commercial contact lens solution. The three most common risk factors for fungal keratitis are contact lens use, trauma and penetrating keratoplasty. (Yildiz et al.) (Iyer et al., 2006) Filamentous fungi form the majority of causative organisms with Fusarium (41\%), Candida (14\%), Aspergillus (12\%) and Curvularia (12\%) being among the top contenders.(Iyer et al., 2006; Jurkunas et al., 2009) Fungal infections of the cornea, if not treated immediately and managed appropriately, can rapidly lead to corneal ulceration, perforation, corneal neovascularisation, loss of vision and possibly, loss of the eye. (Yuan \& Wilhelmus, 2009) (Thomas, P. A. \& Geraldine, 2007) It is thus imperative to understand the molecular underpinnings of fungal keratitis, especially the involvement of immune players, for a more thorough understanding towards devising novel and efficacious treatment modalities.

Contact lens wear can compromise the integrity of the corneal epithelium, making it susceptible to fungal invasion. It is known that contact lens wear can induce a subclinical host immune response with recruitment of LCs into the cornea. (Sankaridurg et al., 2000) TLRs on APCs, such as LCs or macrophages, recognize fungi, thereby activating the innate and adaptive immune response to clear the infection.(Barton \& Medzhitov, 2003; Johnson et al., 2005) Hu et al. demonstrated the importance of macrophages through depletion of these cells, showing the contribution of macrophages in two different fungal infection models 5 and 7 days following infection. In this study development of more severe keratomycosis in mice depleted of macrophages points the contribution of macrophages in limiting fungal disease. (Hu et al., 2009) In vitro studies have shown that inactivated hyphae of Fusarium solani upregulate gene expression of TLRs-2, 3, 4 and 6, along with protein expression of TLRs 2 and 4 with resultant increases in cytokine expression of IL-6 and IL-8. The importance of TLR-4 in modulating the host defense mechanisms to fungi, especially Fusarium keratitis, has been demonstrated by several groups. In an experimental model of infectious keratitis, it was observed that resolution of Fusarium keratitis involved activation of both the innate immune response along with the adaptive arm through TLR-4.(Sun et al.) In another murine study, inoculation in knockout models of TLR-4, lead to impaired host anti-fungal defense mechanisms, decreased production of CXCL1 with subsequent decreased recruitment of neutrophils into the cornea, as well as uncontrolled fungal growth and eventually corneal perforation (Tarabishy et al., 2008) On the contrary, hydrocortisone treatment in vitro leads to a TLR-mediated increase in resistance to Fusarium solani with a concomitant increase in IL-6 expression by human corneal endothelial cells (HCEC).(Jin et al., 2007)

Similarly, in humans, fungal keratitis secondary to Aspergillus and Candida species also rely on human corneal TLRs 2 and 4 for hosting an immune response.(Mambula et al., 2002; Netea et al., 2002; Netea et al., 2003) TLRs 2 and 4 recognise fungal zymosan and mannan, leading to an expected increase in the production of IL-6 and IL-1 $\beta$ when challenged with Aspergillus, which is diminished by knocking down these innate receptors, confirming the 
putative role of TLRs 2 and 4 in Aspergillus keratitis.(Guo \& Wu, 2009) In a recent study from the same group investigated the effect of targeting TLR2 by a small interfering RNA (siRNA) construct applied subconjunctively and topically to the cornea, showed that suppressing TLR2 expression in the cornea results in a decrease in neutrophil infiltration, allowing the cornea to preserve its morphological integrity. Suppressing TLR2 expression also caused a decrease in TNF- $\alpha$, IL-1 $\beta$, IL-6, IL-12, monocyte chemoattractant protein (MCP1)/CCL2 and macrophage inflammatory protein (MIP-2)/CXCL2 expression. Immunomodulation by targeting TLR2 might be a treatment approach in fungal keratitis to avoid damage to the cornea by an immune response.(Guo et al.) Aspergillus fumigatus also induces IL-10 expression, and taken together, these cytokines attract and direct PMNs into the cornea, inciting innate immunity.(Redfern \& McDermott) Thus, in addition to antifungal therapy, modulating fungus-specific TLR responses and controlling the host's immune response to the patient's advantage, is an exciting avenue to explore in the field of molecular anti-fungal therapy towards quicker resolution of infection with minimal residual damage.

\subsubsection{Acanthamoeba keratitis}

Acanthamoeba keratitis (AK) is a resilient, vision-threatening infection of the cornea. Acanthamoeba is an ubiquitous protozoa, which is exceptionally difficult to treat. Infection with Acanthamoeba either resolves spontaneously, or, as often seen, results in progressive infection and eventual corneal melting, suggesting a role of the immune system in its pathophysiology. Corneal transplantation is indicated in cases of severe infection, however, reinfection can commonly occur due to the presence of Acanthamoeba cysts within the host graft bed. Reinfection and recrudescence indicates the absence of memory against this parasite, and hence a poor activation of the adaptive arm of the immune response. Acanthamoeba species exist freely in the environment and on certain mucosal surfaces of healthy individuals.(Alizadeh et al. 1996; Niederkorn et al. 1999) Two of the most critical risk factors for AK include contact lens use and corneal trauma.(Niederkorn et al. 1999) Trophozoites attach to the surface of the contact lens which are then introduced to the ocular surface. Integrity of the host immune machinery predicts the severity of infection and incidence of disease as patients with AK have lower tear levels of IgA against Acanthamoeba antigens as compared to healthy controls, implicating the role of mucosa-mediated immunity in AK. (Alizadeh et al. 2001) The unique resilience of the double-layered cellulose wall of Acanthamoeba cysts, which are resistant to extreme temperatures, UV and gamma irradiation, underlies the challenges of treating AK. Systemic immunization to Acanthamoeba antigens does not confer immunity unlike mucosa-induced immunity.

Once the trophozoites invade the corneal epithelium through dislodgement of the epithelial cells caused by contact-lens induced microabrasions, there is a TLR-4-mediated immune response in corneal epithelial cells with release of cytokines IL-8 and TNF- $\alpha$ as shown in rats (Ren and $\mathrm{Wu}$ 2011). The innate immune response is activated with recruitment of neutrophils and macrophages. Macrophages are believed to be pivotal to the resolution of AK. They have a chemotactic response to the pathogen, and bear an inherent ability to kill the trophozoites in vivo. This phenomenon can be demonstrated by the depletion of macrophages in Clodronate treated animals which develop severe, chronic AK. (Stewart et al. 1992; van Klink et al. 1996) Although cysts are more difficult to eradicate, macrophages 
forming the first line of defence in AK may also attack Acanthamoeba cysts by direct phagocytosis as seen in vitro (Hurt et al. 2003). Like macrophages, neutrophils also form the first-line defence against both Acanthamoeba cysts and trophozoites, but demonstrate a more robust and efficient response. They are found in large numbers in corneas with AK, where they clear the protozoan using myeloperoxidase-dependent killing. Neutrophils are important both in the prevention and resolution of AK.(Hurt et al. 2003; Clarke et al. 2005).

The most convincing and potent response from the adaptive arm of the immune system is the secretion of $\operatorname{IgA}$ antibody. IgA antibody promotes neutrophil-mediated killing of trophozoites hence preventing adhesion of the trophozoites to the corneal epithelium. Furthermore, it shuts down the corneal melt-down plant of the trophozoites by inhibiting mannose-induced cytopathic protein 133 (MIP-133)-induced digestion of the corneal epithelium and stroma. The role of corticosteroids in the treatment of AK remains controversial. This issue arises from the contrary effects of dexamethasone on the eye; on the one hand they help in the resolution of AK-associated ocular inflammation, but on the other hand, they induce excystment of dormant cysts leading to recrudescence. Thus, targeting MIP-133 offers an attractive target in the therapy of AK. Earlier detection of disease by visualization of cysts in the cornea using in vivo confocal microscopy (IVCM) may offer an advantage in the management of AK.(Kumar et al. 2010) Through a more sensitive approach in the detection and consequent treatment of $\mathrm{AK}$, the prognosis may be improved leading to fewer cases of corneal melting and associated complications.

\subsection{Corneal transplantation}

Corneal transplantation is the most common form of solid tissue transplantation with approximately 45,000 cases being performed annually in the United States alone.(CCTS, 1992; Niederkorn, 1999; Streilein, 1999) Unlike other solid tissue transplants, corneal allotransplants enjoy immune privilege, and neither require standard human leukocyte antigen (HLA) matching, nor permanent systemic immunosuppression. First time recipients of corneal allografts enjoy a 2-year graft survival rate of greater than $90 \%$ if the recipient corneal bed is avascular and free of inflammation.(Niederkorn, 1990) Corneal immune privilege is attributed to: (a) an avascular corneal bed which prevents recruitment of immune cells and leukocytes to the graft site, thus preventing recognition of non-self HLA antigens; (b) lack of lymphatic vessels, which eliminates transport and presentation of nonself HLA antigens and egress of APCs to T cells in draining lymph nodes, thus decreasing sensitisation (c) paucity of mature $\mathrm{MHC}-\mathrm{II}^{+} / \mathrm{HLA}-\mathrm{DR}^{+}$resident corneal dendritic cells, including LC, thus decreasing direct presentation of unmatched HLA antigens to T cells; (d) constitutive expression of Fas ligand (CD95; FasL), which programs cell death of activated Fas $^{+} \mathrm{T}$ cells; (e) local ocular production of immunomodulatory neuropeptides and factors in aqueous humour such as transforming growth factor beta (TGF)- $\beta_{2}$ and alpha-melanocyte stimulating hormone $(\alpha-\mathrm{MSH})$, which inhibits alloantigen-driven $\mathrm{T}$ cell activation and DTH.(Dana, M. R. et al., 2000; Dua \& Azuara-Blanco, 1999; Griffith et al., 1995; Jager et al., 1995; Niederkorn, 1990; Niederkorn et al., 1989; Streilein, 1993, 1995; Stuart et al., 1997; Thiel et al., 2009)

Neovascularization of the corneal graft greatly increases the rate of rejection.(Alldredge \& Krachmer, 1981; Maguire et al., 1994) As per guidelines of the Collaborative Corneal Transplantation Studies, the recipient cornea is considered "high-risk" if there is stromal 
vascularisation in two or more quadrants preoperatively.(1992) The other factors which lead to graft rejection include growth of lymphatic vessels into the cornea, thereby establishing drainage to the cervical lymph nodes;(Hamrah et al., 2002a) migration of LCs into the cornea; maturation of resident LCs and DCs of the cornea, which can then serve as APCs;(Dekaris et al., 1999; Hamrah \& Dana, 2007; Hamrah et al., 2002b; Liu et al., 2002) increased expression of cytokines IL-1 and TNF- $\alpha$, which lead to recruitment of neutrophils, suppression of anterior chamber-associated immune deviation (ACAID), maturation of corneal APCs, upregulation of vascular adhesion molecules, and recruitment of leukocytes.(Dana, M. R. \& Streilein, 1996; Dana, R., 2007; Hamrah et al., 2007; Pepose et al., 1985; Streilein et al., 1996; Yamagami et al., 1999; Zhu, S. et al., 1999; Zhu, S. N. \& Dana, 1999)

The process of corneal transplant rejection includes an induction phase, called the "afferent" arm, and an expression phase, called the "efferent" arm. In the afferent arm, the host becomes sensitized to the donor antigens by APCs (e.g., MHC class II-positive DC, LC, macrophages, etc.) that present antigens to $\mathrm{T}$ cells in draining lymph nodes. This sensitization process involves two different pathways. The direct pathway, which involves donor APCs that sensitize the host directly when T cells recognize the donor class II MHC, thus generating direct alloreactive $\mathrm{T}$ cells, and the indirect pathway, which involves host APCs that migrate to the graft, take up donor antigens, process it, migrate to draining lymph nodes, and then present their antigens to T cells. Host sensitization to donor antigens of corneal grafts occurs through both pathways of sensitization, especially in high-risk corneal grafting. Further, the critical role of draining cervical lymph nodes in the process of allosensitization has been clearly demonstrated by recent studies. Upon arrival in the lymph nodes, APCs upregulate surface expression of co-stimulatory molecules, secrete cytokines, leading to activation of $\mathrm{T}$ cells. The subsequent efferent phase is then responsible for the actual rejection of the graft. This phase consists of the proliferation of alloreactive $\mathrm{T}$ cells in lymphoid organs, migration of these cells to the cornea, and the development of "memory" that can assist the alloimmune response in case of repeated exposure to the same antigens. Both $\mathrm{CD}^{+}$cytotoxic $\mathrm{T}$ lymphocyte (CTL) and $\mathrm{CD} 4^{+} \mathrm{T}$ helper (Th) cells have been implicated in the rejection process. Th1 cells uniquely secrete IL-2, IFN- $\gamma$, and lymphotoxin, and have the purpose of eradicating offending pathogens by promoting inflammation. Th2 cells secrete IL-4 and IL-10, suppress Th1 cells, and promote B cell differentiation, leading to the production of antibodies. CD4 ${ }^{+} \mathrm{Th} 1$ cells are the primary mediators of the efferent arm and act directly as effector cells and not as helper cells in corneal graft rejection. IL-2, secreted by these cells, stimulates the activation and proliferation of other T and B cells, whereas IFN- $\gamma$ activates macrophages and induces expression of class II antigens in the donor tissue. The role of $\mathrm{CD}^{+} \mathrm{T}$ cells in the rejection of allogeneic corneal grafts remains controversial. While $\mathrm{CD}^{+} \mathrm{T}$ cells can contribute to graft rejection, corneal grafts can still be rejected in their absence, hence making $\mathrm{CD}^{+} \mathrm{T}$ cells sufficient but not necessary for graft rejection.

A major factor directing the recruitment of $\mathrm{T}$ cells and other leukocytes into grafts are chemokines. Surgical trauma induces release of early cytokines such as TNF- $\alpha$ and IL- 1 by corneal epithelial cells. These cytokines in turn stimulate the production of early neutrophiland macrophage-attractant chemokines, including MIP-2/CXCL2, MCP-1/CCL2, regulated upon activation normal T-cell expressed and secreted protein (RANTES)/CCL5, MIP-

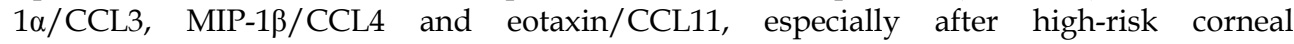


transplantation.(Flynn et al., 2008; Yamagami et al., 2005; Yamagami et al., 2000; Yamagami et al., 1999) While early chemokines direct non-antigen-specific leukocytes to the graft, late chemokines as stated above produced by the graft and infiltrating leukocytes recruit alloantigen-primed $\mathrm{T}$ cells into the graft. In addition, recipients of high-risk transplants express very high levels of the IP-10/CXCL10 chemokine. Chemokines function together with other molecular mediators including integrins and adhesion molecules to direct the immune response toward the graft. Therapeutic endeavours seek to inhibit either or both arms of the immune response to prolong graft survival. Regulatory $\mathrm{T}$ cells (Foxp $3^{+} \mathrm{T}_{\text {regs }}$ ) have been shown to promote graft survival by inhibiting alloimmunity in draining lymph nodes as opposed to altering to the effector arm of the immune response.(Chauhan et al., 2009; Cunnusamy et al.; Tang \& Bluestone, 2008) Measures devised to enhance graft survival should essentially revolve around three main goals: (a) to prevent induction of alloimmune response, (b) to inhibit or deplete immune effector cells, and, (c) to induce tolerance to specific alloantigens.(Niederkorn, 2002)

\subsection{Dry Eye Disease}

Dry eye disease (DED) is one of the most common diagnoses made in ophthalmic practice. DED affects millions of people around the world. It is more prevalent in women than men and is of inflammatory etiology.(Calonge et al.; 2007b) In epidemiologic studies conducted by Schaumberg and colleagues, they found a prevalence of $5.7 \%$ in women aged 50 years or younger, and $9.8 \%$ in women aged 75 years or above.(Schaumberg et al., 2003) Patients usually present with ocular irritation and in severe cases, there may be accompanying ocular pain, punctate keratopathy and filamentary keratitis.(Pflugfelder, 1998) The definition of DED has been modified over the years to integrate evolving concepts of the involvement of tear film hyperosmolarity, inflammation of the ocular surface, and the effects of DED on vision. In 2007, the International Dry Eye Workshop (DEWS) defined DED as: "a multifactorial disease of the tears and ocular surface that results in symptoms of discomfort, visual disturbance, and tear film instability with potential damage to the ocular surface. It is accompanied by increased osmolarity of the tear film and inflammation of the ocular surface."(DEWS, 2007a)

Clinically, DED can be categorised into (a) aqueous deficient and, (b) evaporative dry eye. (Lemp, 1995) Aqueous deficient DED consists of disorders that affect the lacrimal functional unit (LFU). The term "lacrimal functional unit" was coined in 1998 by Stern and group, comprising the ocular surface, lacrimal glands, associated innervation, and neuroendocrine factors.(Stern et al., 1998; Stern et al., 2004) The clinical diagnosis of DED is made using a combination of examination techniques, including Schirmer's test, tear film osmolarity, and fluorescein tear break-up time (fTBUT). A reading of less than $15 \mathrm{~mm}$ on the Schirmer's strip in conjunction with elevated tear film osmolarity $(>315 \mathrm{mOsm})$ is indicative of decreased tear production, hence, suggestive of aqueous-deficient DED. When fTBUT is less than 10 seconds, there is increased suspicion of evaporative DED. Diseases that lead to aqueous deficient dry eye disease include Sjögren's syndrome and non-Sjögren's autoimmune conditions. Whereas, evaporative dry eye is due to diseases that affect the production, quality and distribution of the tear film lipid layer, namely, meibomian gland dysfunction (MGD) and chronic blepharitis.(Barabino \& Dana, 2007; Calonge et al.) It has been demonstrated that regardless of the etiology of dry eye, inflammation of the ocular surface and homing of immune cells to the target tissue, are hallmarks of DED. These immuno- 
inflammatory processes are culprits of corneal and conjunctival damage leading to the presenting symptoms.(Barabino \& Dana, 2007; Dana, M. R. \& Hamrah, 2002)

Recent evidence suggests a role for chemokines in the pathogenesis of dry eye syndromes. Increased RNA levels of IL-8, which is chemotactic for neutrophils, are found in the conjunctival epithelium of Sjogren's syndrome patients compared to controls. Furthermore, increased levels of select chemokines in the lacrimal glands of nonobese diabetic (NOD) mice, an animal model of Sjogren's syndrome, have been detected. NOD mice are a murine model for type- 1 insulindependent diabetes with an autoimmune component. They represent a murine model of Sjogren's syndrome based on the similar histopathological picture of sialoadenitis. These mice have lymphocytic infiltration of not just the pancreas but also the submandibular and lacrimal glands. Both RANTES/CCL5 and IP-10/CXCL10 gene transcripts are detected in lacrimal glands at 8 weeks of age increased markedly during the course of active disease, concomitant with induction of their receptors CCR1, CCR5 and CXCR3. The examination of lacrimal glands indicated that lymphocytes in the inflammatory infiltrates are responsible for the production of these chemokines. Moreover, anti-RANTES treatment significantly reduced inflammation in the lacrimal glands of these mice. Further, patients with DED have a significant increase in the number of ocular surface cells that express CCR5, the receptor for RANTES/CCL5 and MIP$1 \beta / C C L 4$. These data suggest that a better understanding of the role of chemokines and chemokine receptors in DES could open new doors for development of molecular strategies for immune modulation in this common disorder.

Numerous studies have demonstrated the enhanced expression of pro-inflammatory cytokines (e.g., IL-1, IL-6, IL-8, TNF- $\alpha$ ) mRNA and protein by the ocular surface epithelium or tear film. The increase of these proinflammatory cytokines can lead to epithelial cell proliferation, keratinization, and angiogenesis, and thereby could link ocular surface disease with a number of lid margin disorders, such as rosacea, characterized by inflammation. In addition, IL-1 may lead to upregulation of matrix proteases, including collagenases, and thereby exacerbate stromal pathology as well as alter the paracrine effect of other cytokines on resident DCs, macrophages, fibroblasts, and epithelial cells by altering the matrix milieu in which these cytokines bind their respective receptors. Corneal epithelial cells respond to stress signals by producing cytokine mediators of inflammation such as TNF- $\alpha$, IL-1 $\beta$, IL- 8 and MMPs.(Li et al., 2006; Luo et al., 2004) Subsequently, maturing resident and recruited DC carry antigen to the draining lymph nodes to present and activate $T$ cells. $T$ cellmediated responses have recently been shown to play a center stage in DED. Th1 cells recognize antigenic peptides in association with MHC class II molecules on the surface of APC, and release pro-inflammatory cytokines that increase vascular permeability and recruit further inflammatory cells to the site of injury. Due to the nonspecific nature of cell recruitment employed by CD4+ Th1 cells, inflammation can be severe with damage to bystander tissue. More recently, Th 17 associated cytokines and IL 17 producing cells have been found in the ocular surface epithelium of dry eye patients and it has been hypothesized that epithelial cells subjected to desiccating conditions promote DC to secrete IL-6, IL-23 and TGF- $\beta$, which in turn induce Th17 cells.(Zheng, X. et al.)

\section{Leukocyte trafficking}

Trafficking signals finely control the movement of distinct subsets of immune cells into and out of specific tissues. Leukocyte extravasation from blood to tissue, including that of APC 
and T cells, usually occurs through a multistep process, involving adhesion molecules and chemokines. Because the accumulation of leukocytes in tissues contributes to a wide variety of diseases, these 'molecular codes' provide new targets for inhibiting tissue-specific inflammation. However, immune cell migration is also critically important for the delivery of protective immune responses to tissues. Therefore, the challenge lies in identifying trafficking molecules that will specifically inhibit key cell subsets that drive disease processes without affecting the migration of leukocytes required for protective immunity.

Adhesion molecules can be categorized according to their structure or function. Four major families are distinguished structurally: the selectins, the sialomucins, the integrins, and the Ig superfamily. Leukocyte tethering and rolling, mediated typically by three selectins, Lselectin, E-selectin and P-selectin, are the first steps in the process of leukocyte binding to vascular endothelium. Two selectins, P- and E-selectin, are expressed on activated endothelium, whereas L-selectin is found on leukocytes. L-selectin is involved in the homing of $\mathrm{T}$ cells to lymphoid tissues but is also expressed on other leukocytes, where it participates in inflammation. E-selectin is expressed on corneal vascular endothelium, whereas P-selectin is expressed on inflamed vascular endothelium and by certain leukocytes. P-selectin glycoprotein ligand-1 (PSGL-1) binds all three selectins and is expressed on peripheral blood DC.

In the cornea, studies in both human and animal models of disease have confirmed that cell adhesion molecules are closely associated with the development of herpetic keratitis, and corneal allograft rejection. P- and E-selectin have been shown to mediate neutrophil recruitment to the cornea in studies using P/E-selectin knockout mice. Integrins are found on most cell types. Two subfamilies are most important for leukocyte migration: the a4 (CD49) and the $\beta 2$ (CD11/CD18) integrins. Four distinct members of $\beta 2$ integrins exist, three of which are expressed by DC. Vascular endothelial ligands for these molecules are members of the immunoglobulin superfamily. Leukocyte arrest in venules requires in situ activation of at least one of the four main integrins: VLA- 4 (binds to VCAM-1), $\alpha 4 \beta 7$ (binds to MadCAM-1), Mac-1(binds to ICAM-1) and LFA-1 (binds to ICAM-1 and 2). VCAM-1 has been shown to be present on monocytes and vascular endothelial cells during corneal inflammation. Arguably the most important ligand for $\beta 2$ integrins is ICAM-1, which is expressed on many cell types and is strongly upregulated upon exposure to inflammatory cytokines in the cornea and on limbal endothelial cells, deletion of which has been shown to suppress corneal graft rejection.

Chemokine receptors regulate leukocyte retention within tissues. The migration of leukocytes to inflammatory sites depends on a cascade of discrete events mediated, in part, by chemokines and their receptors. Numerous chemokines have now been described during inflammation, including CCL3/MIP-1 $\alpha$, CCL4/MIP-1 $\beta$, and CCL5/RANTES, ligands for CCR1 and CCR5; CCL2/MCP-1, a ligand for CCR2; CCL22/MDC and CCL17/TARC, ligands for CCR4; CCL20/MIP-3 $\alpha$, the ligand for CCR6; CXCL8/IL-8, a ligand for CXCR1 and CXCR2; CXCL1/KC, CXCL2/MIP-2, and CXCL5/ENA-78, ligands for CXCR2; CXCL9 /MIG, CXCL10/IP10 and CXCL11/ITAC, ligands for CXCR3. In addition, constitutively expression of CCLs 2-5,CXCL10, and CCL27/CTACK, a ligand for CCR10 have been described in the normal cornea. Which of these chemokines is relevant in recruitment, retention and egrees of corneal APC, is unclear. Little is known about the constitutive recruitment of DC and macrophage precursors into peripheral tissues in the absence of 
inflammation. APC function and migratory behavior are related to rapid and coordinated switching in chemokine receptor expression by these cells, allowing them to coordinate migratory routes and biological function. During inflammation, CCL2, CCL5, and CXCL8 are produced to attract immature DC that express CXCR4 and CCR4 respectively. In addition, these DC are ideally suited for recruitment to inflammatory sites by their expression of functional receptors for inflammation-induced chemokines, such as CCR1, CCR2, CCR3, CCR5 and CXCR1.

Inflammatory signals induce resident corneal DCs to undergo maturation. Upon maturation, DCs downregulate pattern recognition receptors necessary for surveillance of antigens and upregulate CCR7, a receptor important in the homing of DCs to the lymph nodes. Maturing CCR7+ DCs then enter CCL21-expressing lymphatic vessels and travel to the draining lymph nodes where CCR7 ligands, namely, CCL19/EBI1 ligand chemokine (ELC) and CCL21/secondary lymphoid tissue chemokine (SLC), are produced. In addition, after fluorescein isothiocyanate (FITC) painting (dendritic cell migration assay), CXCR4 inhibition has been shown to impair LC and dermal DC migration to draining LNs, indicating that both CCR7 and CXCR4 make independent contributions to the egress of DCs from resident tissue to the lymph nodes. DC migration into and along afferent lymphatics occurs through a series of steps, including (1) mobilization, (2) detachment, (3) interstitial migration, (4) entry into the afferent lymphatics, and (5) transit via lymph. Recent data have shown that lymphatic endothelial cells upregulate E-selectin, chemokines (CCL5, CCL20, and CXCL5), and adhesion molecules (ICAM-1 and VCAM-1) after cytokine stimulation in vitro or in vivo. Once in the draining lymph nodes, antigen-loaded mature DCs activate naive $\mathrm{T}$ cells, which then proliferate and enter the blood and migrate back to the site of inflammation. In the cornea, CCR5 and CX3CR1, but not CCR1 are partially involved in the recruitment of MHC-II+ LCs. How the central immature LC or stromal APC populations are recruited is not known, although the recently demonstrated constitutive expression of CCR2 on stromal BM-derived cell subsets, implicates a role for this chemokine. Further, both vascular endothelial growth factor (VEGFR)-3 and CCR7 are partially implicated in the egress of stromal DCs. APC recruitment to the cornea is likely complex, highly regulated and dependent on recruitment signals that are either tissue-specific or inflammationinduced, or both.

\section{Conclusion}

The cornea and ocular surface are constantly exposed to environmental pollutants and irritants, microbes, and other potentially noxious agents. Since from an evolutionary standpoint the scope of the host defense mechanisms against these stimuli should be narrow, that is to say adequately effective to protect the eye against the potential harm from these agents and yet tempered enough not to lead to unwanted damage, the eye has developed many mechanisms to effect and regulate its response to environmental challenges. Identification of the critical pathways of cell migration to and from the cornea will provide new molecular targets for pharmacological intervention in inflammatory, infectious, alloimmune and autoimmune diseases and may lead to novel highly specific strategies for immunotherapy, through modulation of APC and T cell migration and function. Few effective anti-inflammatory drugs have emerged over the last decades in the ophthalmic field and an urgent need for new drugs exists, as many inflammatory diseases are inadequately responsive to current medications. 


\section{References}

Akhtar, J. \& Shukla, D. (2009). Viral entry mechanisms: cellular and viral mediators of herpes simplex virus entry. FEBS J. 276: 7228-7236.

Alizadeh, H., Niederkorn, J.Y., McCulley, J.P., in: Pepose, J.S., Holland, G.N., Wilhelmus, K.R. (Eds.), Ocular Infection and Immunity, Mosby, St. Louis, 1996, pp. 1062e1071.

Alizadeh H, Apte S, El-Agha MS, Li, L. Hurt, M. Howard, K. Cavanagh, H. D. McCulley, J. P. Niederkorn, J.Y. (2001) Tear IgA and serum IgG antibodies against Acanthamoeba in patients with Acanthamoeba keratitis. Cornea. 20:622-627.

Alldredge, O.C. \& Krachmer, J.H. (1981). Clinical types of corneal transplant rejection. Their manifestations, frequency, preoperative correlates, and treatment. Arch Ophthalmol. 99: 599-604.

Asbell, P.A. \& Kamenar, T. (1987). The response of Langerhans cells in the cornea to herpetic keratitis. Curr Eye Res. 6: 179-182.

Avery, A.C., Zhao, Z.S., Rodriguez, A., Bikoff, E.K., Soheilian, M., Foster, C.S., \& Cantor, H. (1995). Resistance to herpes stromal keratitis conferred by an IgG2a-derived peptide. Nature. 376: 431-434.

Babu, J.S., Kanangat, S., \& Rouse, B.T. (1995). T cell cytokine mRNA expression during the course of the immunopathologic ocular disease herpetic stromal keratitis. J Immunol. 154: 4822-4829.

Babu, J.S., Thomas, J., Kanangat, S., Morrison, L.A., Knipe, D.M., \& Rouse, B.T. (1996). Viral replication is required for induction of ocular immunopathology by herpes simplex virus. J Virol. 70: 101-107.

Balkwill, F.R. \& Burke, F. (1989). The cytokine network. Immunol Today. 10: 299-304.

Barabino, S. \& Dana, M.R. (2007). Dry eye syndromes. Chem Immunol Allergy. 92: 176-184.

Barton, G.M. \& Medzhitov, R. (2003). Toll-like receptor signaling pathways. Science. 300: 1524-1525.

Bauer, D., Wasmuth, S., Hennig, M., Baehler, H., Steuhl, K.P., \& Heiligenhaus, A. (2009). Amniotic membrane transplantation induces apoptosis in T lymphocytes in murine corneas with experimental herpetic stromal keratitis. Invest Ophthalmol Vis Sci. 50: 3188-3198.

Bouley, D.M., Kanangat, S., Wire, W., \& Rouse, B.T. (1995). Characterization of herpes simplex virus type-1 infection and herpetic stromal keratitis development in IFNgamma knockout mice. J Immunol. 155: 3964-3971.

Brandt, C.R. \& Salkowski, C.A. (1992). Activation of NK cells in mice following corneal infection with herpes simplex virus type-1. Invest Ophthalmol Vis Sci. 33: 113-120.

Burns, A.R., Li, Z., \& Smith, C.W. (2005). Neutrophil migration in the wounded cornea: the role of the keratocyte. Ocul Surf. 3: S173-176.

Calonge, M., Enriquez-de-Salamanca, A., Diebold, Y., Gonzalez-Garcia, M.J., Reinoso, R., Herreras, J.M., \& Corell, A. (2010). Dry eye disease as an inflammatory disorder. Ocul Immunol Inflamm. 18: 244-253.

Campadelli-Fiume, G., Amasio, M., Avitabile, E., Cerretani, A., Forghieri, C., Gianni, T., \& Menotti, L. (2007). The multipartite system that mediates entry of herpes simplex virus into the cell. Rev Med Virol. 17: 313-326.

Carr, D.J., Harle, P., \& Gebhardt, B.M. (2001). The immune response to ocular herpes simplex virus type 1 infection. Exp Biol Med (Maywood). 226: 353-366. 
Carr, D.J., Wuest, T., \& Ash, J. (2008). An increase in herpes simplex virus type 1 in the anterior segment of the eye is linked to a deficiency in NK cell infiltration in mice deficient in CXCR3. J Interferon Cytokine Res. 28: 245-251.

Carubelli, R., Nordquist, R.E., \& Rowsey, J.J. (1990). Role of active oxygen species in corneal ulceration. Effect of hydrogen peroxide generated in situ. Cornea. 9: 161-169.

Chatterjee, S., Lakeman, A.D., Whitley, R.J., \& Hunter, E. (1984). Effect of cloned human interferons on the replication of and cell fusion induced by herpes simplex virus. Virus Res. 1: 81-87.

Chauhan, S.K., Saban, D.R., Lee, H.K., \& Dana, R. (2009). Levels of Foxp3 in regulatory T cells reflect their functional status in transplantation. J Immunol. 182: 148-153.

Chen, S.H., Oakes, J.E., \& Lausch, R.N. (1994). Synergistic anti-herpes effect of TNF-alpha and IFN-gamma in human corneal epithelial cells compared with that in corneal fibroblasts. Antiviral Res. 25: 201-213.

Clarke DW, Alizadeh H, Niederkorn, J.Y. (2005). Failure of Acanthamoeba castellanii to produce intraocular infections. Invest Ophthalmol Vis Sci. 46:2472-2478.

Cole, N., Bao, S., Willcox, M., \& Husband, A.J. (1999). Expression of interleukin-6 in the cornea in response to infection with different strains of Pseudomonas aeruginosa. Infect Immun. 67: 2497-2502.

Cunnusamy, K., Chen, P.W., \& Niederkorn, J.Y. (2011). IL-17A-Dependent CD4+CD25+ Regulatory $\mathrm{T}$ Cells Promote Immune Privilege of Corneal Allografts. J Immunol. 186: 6737-6745.

Daheshia, M., Kanangat, S., \& Rouse, B.T. (1998). Production of key molecules by ocular neutrophils early after herpetic infection of the cornea. Exp Eye Res. 67: 619-624.

Dana, M.R., Dai, R., Zhu, S., Yamada, J., \& Streilein, J.W. (1998). Interleukin-1 receptor antagonist suppresses Langerhans cell activity and promotes ocular immune privilege. Invest Ophthalmol Vis Sci. 39: 70-77.

Dana, M.R. \& Hamrah, P. (2002). Role of immunity and inflammation in corneal and ocular surface disease associated with dry eye. Adv Exp Med Biol. 506: 729-738.

Dana, M.R., Qian, Y., \& Hamrah, P. (2000). Twenty-five-year panorama of corneal immunology: emerging concepts in the immunopathogenesis of microbial keratitis, peripheral ulcerative keratitis, and corneal transplant rejection. Cornea. 19: 625-643.

Dana, M.R. \& Streilein, J.W. (1996). Loss and restoration of immune privilege in eyes with corneal neovascularization. Invest Ophthalmol Vis Sci. 37: 2485-2494.

Dana, R. (2007). Comparison of topical interleukin-1 vs tumor necrosis factor-alpha blockade with corticosteroid therapy on murine corneal inflammation, neovascularization, and transplant survival (an American Ophthalmological Society thesis). Trans Am Ophthalmol Soc. 105: 330-343.

Dekaris, I., Zhu, S.N., \& Dana, M.R. (1999). TNF-alpha regulates corneal Langerhans cell migration. J Immunol. 162: 4235-4239.

Dua, H.S. \& Azuara-Blanco, A. (1999). Corneal allograft rejection: risk factors, diagnosis, prevention, and treatment. Indian J Ophthalmol. 47: 3-9.

Ellison, A.R., Yang, L., Cevallos, A.V., \& Margolis, T.P. (2003). Analysis of the herpes simplex virus type 1 UL6 gene in patients with stromal keratitis. Virology. 310: 2428.

Farris, R. (1998). Abnormalities of the tears and treatment of dry eyes. in The Cornea (ed. HE Kauffman, B.B., MB McDonald), pp. p109-130. Butterworth-Heinemann, Boston. 
Flynn, T.H., Mitchison, N.A., Ono, S.J., \& Larkin, D.F. (2008). Aqueous humor alloreactive cell phenotypes, cytokines and chemokines in corneal allograft rejection. Am J Transplant. 8: 1537-1543.

Foster, C.S., Rodriguez Garcia, A., Pedroza-Seres, M., Berra, A., Heiligenhaus, A., Soukiasian, S., \& Jayaraman, S. (1993). Murine herpes simplex virus keratitis is accentuated by CD4+, V beta 8.2+ Th2 T cells. Trans Am Ophthalmol Soc. 91: 325348; discussion 349-350.

Ghiasi, H., Cai, S., Perng, G.C., Nesburn, A.B., \& Wechsler, S.L. (2000). The role of natural killer cells in protection of mice against death and corneal scarring following ocular HSV-1 infection. Antiviral Res. 45: 33-45.

Ghiasi, H., Cai, S., Slanina, S.M., Perng, G.C., Nesburn, A.B., \& Wechsler, S.L. (1999). The role of interleukin (IL)-2 and IL-4 in herpes simplex virus type 1 ocular replication and eye disease. J Infect Dis. 179: 1086-1093.

Griffith, T.S., Brunner, T., Fletcher, S.M., Green, D.R., \& Ferguson, T.A. (1995). Fas ligandinduced apoptosis as a mechanism of immune privilege. Science. 270: 1189-1192.

Group, T.C.C.T.S.R. (1992). The collaborative corneal transplantation studies (CCTS). Effectiveness of histocompatibility matching in high-risk corneal transplantation. The Collaborative Corneal Transplantation Studies Research Group. Arch Ophthalmol. 110: 1392-1403.

Guo, H., Gao, J., \& Wu, X. (2011). Toll-like receptor 2 siRNA suppresses corneal inflammation and attenuates Aspergillus fumigatus keratitis in rats. Immunol Cell Biol.

Guo, H. \& Wu, X. (2009). Innate responses of corneal epithelial cells against Aspergillus fumigatus challenge. FEMS Immunol Med Microbiol. 56: 88-93.

Hamrah, P. \& Dana, M.R. (2007). Corneal antigen-presenting cells. Chem Immunol Allergy. 92: 58-70.

Hamrah, P., Huq, S.O., Liu, Y., Zhang, Q., \& Dana, M.R. (2003a). Corneal immunity is mediated by heterogeneous population of antigen-presenting cells. J Leukoc Biol. 74: 172-178.

Hamrah, P., Liu, Y., Zhang, Q., \& Dana, M.R. (2003b). Alterations in corneal stromal dendritic cell phenotype and distribution in inflammation. Arch Ophthalmol. 121: 1132-1140.

Hamrah, P., Liu, Y., Zhang, Q., \& Dana, M.R. (2003c). The corneal stroma is endowed with a significant number of resident dendritic cells. Invest Ophthalmol Vis Sci. 44: 581-589.

Hamrah, P., Yamagami, S., Liu, Y., Zhang, Q., Vora, S.S., Lu, B., Gerard, C.J., \& Dana, M.R. (2007). Deletion of the chemokine receptor CCR1 prolongs corneal allograft survival. Invest Ophthalmol Vis Sci. 48: 1228-1236.

Hamrah, P., Zhang, Q., \& Dana, M.R. (2002a). Expression of vascular endothelial growth factor receptor-3 (VEGFR-3) in the conjunctiva--a potential link between lymphangiogenesis and leukocyte trafficking on the ocular surface. Adv Exp Med Biol. 506: 851-860.

Hamrah, P., Zhang, Q., Liu, Y., \& Dana, M.R. (2002b). Novel characterization of MHC class II-negative population of resident corneal Langerhans cell-type dendritic cells. Invest Ophthalmol Vis Sci. 43: 639-646.

Hazlett, L.D. (2004). Corneal response to Pseudomonas aeruginosa infection. Prog Retin Eye Res. 23: 1-30. 
Hazlett, L.D., McClellan, S., Barrett, R., \& Rudner, X. (2001). B7/CD28 costimulation is critical in susceptibility to Pseudomonas aeruginosa corneal infection: a comparative study using monoclonal antibody blockade and CD28-deficient mice. J Immunol. 166: 1292-1299.

Hazlett, L.D., McClellan, S.A., Rudner, X.L., \& Barrett, R.P. (2002). The role of Langerhans cells in Pseudomonas aeruginosa infection. Invest Ophthalmol Vis Sci. 43: 189-197.

Hazlett, L.D., Rosen, D.D., \& Berk, R.S. (1978). Age-related susceptibility to Pseudomonas aeruginosa ocular infections in mice. Infect Immun. 20: 25-29.

Heiligenhaus, A., Bauer, D., Zheng, M., Mrzyk, S., \& Steuhl, K.P. (1999). CD4+ T-cell type 1 and type 2 cytokines in the HSV-1 infected cornea. Graefes Arch Clin Exp Ophthalmol. 237: 399-406.

Hendricks, R.L. (1997). An immunologist's view of herpes simplex keratitis: Thygeson Lecture 1996, presented at the Ocular Microbiology and Immunology Group meeting, October 26, 1996. Cornea. 16: 503-506.

Hendricks, R.L., Janowicz, M., \& Tumpey, T.M. (1992a). Critical role of corneal Langerhans cells in the CD4- but not CD8-mediated immunopathology in herpes simplex virus1-infected mouse corneas. J Immunol. 148: 2522-2529.

Hendricks, R.L. \& Tumpey, T.M. (1990). Contribution of virus and immune factors to herpes simplex virus type I-induced corneal pathology. Invest Ophthalmol Vis Sci. 31: 19291939.

Hendricks, R.L., Tumpey, T.M., \& Finnegan, A. (1992b). IFN-gamma and IL-2 are protective in the skin but pathologic in the corneas of HSV-1-infected mice. J Immunol. 149: 3023-3028.

Hendricks, R.L., Weber, P.C., Taylor, J.L., Koumbis, A., Tumpey, T.M., \& Glorioso, J.C. (1991). Endogenously produced interferon alpha protects mice from herpes simplex virus type 1 corneal disease. J Gen Virol. 72 ( Pt 7): 1601-1610.

$\mathrm{Hu}$, J., Wang, Y., \& Xie, L. (2009). Potential role of macrophages in experimental keratomycosis. Invest Ophthalmol Vis Sci. 50: 2087-2094.

Huang, X., Barrett, R.P., McClellan, S.A., \& Hazlett, L.D. (2005). Silencing Toll-like receptor-9 in Pseudomonas aeruginosa keratitis. Invest Ophthalmol Vis Sci. 46: 4209-4216.

Hurt M, Proy V, Niederkorn JY, Alizadeh H. (2003) The interaction of Acanthamoeba castellanii cysts with macrophages and neutrophils. J Parasitol. 89:565-572.

Iyer, S.A., Tuli, S.S., \& Wagoner, R.C. (2006). Fungal keratitis: emerging trends and treatment outcomes. Eye Contact Lens. 32: 267-271.

Jager, M.J., Atherton, S., Bradley, D., \& Streilein, J.W. (1991). Herpetic stromal keratitis in mice: less reversibility in the presence of Langerhans cells in the central cornea. Curr Eye Res. 10 Suppl: 69-73.

Jager, M.J., Bradley, D., Atherton, S., \& Streilein, J.W. (1992). Presence of Langerhans cells in the central cornea linked to the development of ocular herpes in mice. Exp Eye Res. 54: 835-841.

Jager, M.J., Bradley, D., \& Streilein, J.W. (1995). Immunosuppressive properties of cultured human cornea and ciliary body in normal and pathological conditions. Transpl Immunol. 3: 135-142.

Janeway C, T.P., Walport M, Shlomchik M. (2004). Immunobiology. Garland Science.

Jayaraman, S., Heiligenhaus, A., Rodriguez, A., Soukiasian, S., Dorf, M.E., \& Foster, C.S. (1993). Exacerbation of murine herpes simplex virus-mediated stromal keratitis by Th2 type T cells. J Immunol. 151: 5777-5789. 
Jin, X., Lin, Z., \& Xie, X. (2010). The delayed response of Toll-like receptors may relate to Pseudomonas aeruginosa keratitis exacerbating rapidly at the early stages of infection. Eur J Clin Microbiol Infect Dis. 29: 231-238.

Jin, X., Qin, Q., Tu, L., Zhou, X., Lin, Y., \& Qu, J. (2007). Toll-like receptors (TLRs) expression and function in response to inactivate hyphae of Fusarium solani in immortalized human corneal epithelial cells. Mol Vis. 13: 1953-1961.

Johnson, A.C., Heinzel, F.P., Diaconu, E., Sun, Y., Hise, A.G., Golenbock, D., Lass, J.H., \& Pearlman, E. (2005). Activation of toll-like receptor (TLR)2, TLR4, and TLR9 in the mammalian cornea induces MyD88-dependent corneal inflammation. Invest Ophthalmol Vis Sci. 46: 589-595.

Jones, D.B. (1973). Early diagnosis and therapy of bacterial corneal ulcers. Int Ophthalmol Clin. 13: 1-29.

Jurkunas, U., Behlau, I., \& Colby, K. (2009). Fungal keratitis: changing pathogens and risk factors. Cornea. 28: 638-643.

Kabashima, K., Banks, T.A., Ansel, K.M., Lu, T.T., Ware, C.F., \& Cyster, J.G. (2005). Intrinsic lymphotoxin-beta receptor requirement for homeostasis of lymphoid tissue dendritic cells. Immunity. 22: 439-450.

Kennedy, M.C., Rosenbaum, J.T., Brown, J., Planck, S.R., Huang, X., Armstrong, C.A., \& Ansel, J.C. (1995). Novel production of interleukin-1 receptor antagonist peptides in normal human cornea. J Clin Invest. 95: 82-88.

Kijlstra, A. (1994). The role of cytokines in ocular inflammation. Br J Ophthalmol. 78: 885-886.

Kintner, R.L. \& Brandt, C.R. (1995). The effect of viral inoculum level and host age on disease incidence, disease severity, and mortality in a murine model of ocular HSV1 infection. Curr Eye Res. 14: 145-152.

Komatsu, K., Miyazaki, D., Morohoshi, K., Kuo, C.H., Kakimaru-Hasegawa, A., Komatsu, N., Namba, S., Haino, M., Matsushima, K., \& Inoue, Y. (2008). Pathogenesis of herpetic stromal keratitis in CCR5- and/or CXCR3-deficient mice. Curr Eye Res. 33: 736-749.

Kumar RL, Cruzat A, Hamrah P. (2010). Current state of in vivo confocal microscopy in management of microbial keratitis. Semin Ophthalmol. 25:166-170.

Kwon, B. \& Hazlett, L.D. (1997). Association of CD4+ T cell-dependent keratitis with genetic susceptibility to Pseudomonas aeruginosa ocular infection. J Immunol. 159: 62836290.

Lee, S., Zheng, M., Kim, B., \& Rouse, B.T. (2002). Role of matrix metalloproteinase-9 in angiogenesis caused by ocular infection with herpes simplex virus. J Clin Invest. 110: 1105-1111.

Lee, S.K., Choi, B.K., Kang, W.J., Kim, Y.H., Park, H.Y., Kim, K.H., \& Kwon, B.S. (2008). MCP-1 derived from stromal keratocyte induces corneal infiltration of CD4+ T cells in herpetic stromal keratitis. Mol Cells. 26: 67-73.

Lemp, M.A. (1995). Report of the National Eye Institute/Industry workshop on Clinical Trials in Dry Eyes. CLAO J. 21: 221-232.

Li, D.Q., Luo, L., Chen, Z., Kim, H.S., Song, X.J., \& Pflugfelder, S.C. (2006). JNK and ERK MAP kinases mediate induction of IL-1beta, TNF-alpha and IL-8 following hyperosmolar stress in human limbal epithelial cells. Exp Eye Res. 82: 588-596.

Liu, Y., Hamrah, P., Zhang, Q., Taylor, A.W., \& Dana, M.R. (2002). Draining lymph nodes of corneal transplant hosts exhibit evidence for donor major histocompatibility 
complex (MHC) class II-positive dendritic cells derived from MHC class II-negative grafts. J Exp Med. 195: 259-268.

Luo, L., Li, D.Q., Doshi, A., Farley, W., Corrales, R.M., \& Pflugfelder, S.C. (2004). Experimental dry eye stimulates production of inflammatory cytokines and MMP-9 and activates MAPK signaling pathways on the ocular surface. Invest Ophthalmol Vis Sci. 45: 4293-4301.

Maguire, M.G., Stark, W.J., Gottsch, J.D., Stulting, R.D., Sugar, A., Fink, N.E., \& Schwartz, A. (1994). Risk factors for corneal graft failure and rejection in the collaborative corneal transplantation studies. Collaborative Corneal Transplantation Studies Research Group. Ophthalmology. 101: 1536-1547.

Mambula, S.S., Sau, K., Henneke, P., Golenbock, D.T., \& Levitz, S.M. (2002). Toll-like receptor (TLR) signaling in response to Aspergillus fumigatus. J Biol Chem. 277: 39320-39326.

Merad, M., Manz, M.G., Karsunky, H., Wagers, A., Peters, W., Charo, I., Weissman, I.L., Cyster, J.G., \& Engleman, E.G. (2002). Langerhans cells renew in the skin throughout life under steady-state conditions. Nat Immunol. 3: 1135-1141.

Meyers-Elliott, R.H. \& Chitjian, P.A. (1981). Immunopathogenesis of corneal inflammation in herpes simplex virus stromal keratitis: role of the polymorphonuclear leukocyte. Invest Ophthalmol Vis Sci. 20: 784-798.

Miller, J.K., Laycock, K.A., Nash, M.M., \& Pepose, J.S. (1993). Corneal Langerhans cell dynamics after herpes simplex virus reactivation. Invest Ophthalmol Vis Sci. 34: 2282-2290.

Miller, R.L., Meng, T.C., \& Tomai, M.A. (2008). The antiviral activity of Toll-like receptor 7 and 7/8 agonists. Drug News Perspect. 21: 69-87.

Naik, S.H., Metcalf, D., van Nieuwenhuijze, A., Wicks, I., Wu, L., O'Keeffe, M., \& Shortman, K. (2006). Intrasplenic steady-state dendritic cell precursors that are distinct from monocytes. Nat Immunol. 7: 663-671.

Netea, M.G., Van Der Graaf, C.A., Vonk, A.G., Verschueren, I., Van Der Meer, J.W., \& Kullberg, B.J. (2002). The role of toll-like receptor (TLR) 2 and TLR4 in the host defense against disseminated candidiasis. J Infect Dis. 185: 1483-1489.

Netea, M.G., Warris, A., Van der Meer, J.W., Fenton, M.J., Verver-Janssen, T.J., Jacobs, L.E., Andresen, T., Verweij, P.E., \& Kullberg, B.J. (2003). Aspergillus fumigatus evades immune recognition during germination through loss of toll-like receptor-4mediated signal transduction. J Infect Dis. 188: 320-326.

Newell, C.K., Martin, S., Sendele, D., Mercadal, C.M., \& Rouse, B.T. (1989a). Herpes simplex virus-induced stromal keratitis: role of T-lymphocyte subsets in immunopathology. J Virol. 63: 769-775.

Newell, C.K., Sendele, D., \& Rouse, B.T. (1989b). Effects of CD4+ and CD8+ T-lymphocyte depletion on the induction and expression of herpes simplex stromal keratitis. Reg Immunol. 2: 366-369.

Nicas, T.I. \& Iglewski, B.H. (1985). The contribution of exoproducts to virulence of Pseudomonas aeruginosa. Can J Microbiol. 31: 387-392.

Niederkorn, J.Y. (1990). Immune privilege and immune regulation in the eye. Adv Immunol. 48: 191-226.

Niederkorn, J.Y. (1999). The immunology of corneal transplantation. Dev Ophthalmol. 30: 129-140. 
Niederkorn JY, Alizadeh H, Leher H, McCulley JP. (1999) The pathogenesis of Acanthamoeba keratitis.Microbes Infect. 1:437-443.

Niederkorn, J.Y. (2002). Immunology and immunomodulation of corneal transplantation. Int Rev Immunol. 21: 173-196.

Niederkorn, J.Y., Peeler, J.S., Ross, J., \& Callanan, D. (1989). The immunogenic privilege of corneal allografts. Reg Immunol. 2: 117-124.

Niemialtowski, M.G. \& Rouse, B.T. (1992a). Phenotypic and functional studies on ocular T cells during herpetic infections of the eye. J Immunol. 148: 1864-1870.

Niemialtowski, M.G. \& Rouse, B.T. (1992b). Predominance of Th1 cells in ocular tissues during herpetic stromal keratitis. J Immunol. 149: 3035-3039.

O'Callaghan, R.J., Engel, L.S., Hobden, J.A., Callegan, M.C., Green, L.C., \& Hill, J.M. (1996). Pseudomonas keratitis. The role of an uncharacterized exoprotein, protease IV, in corneal virulence. Invest Ophthalmol Vis Sci. 37: 534-543.

O'Keeffe, M., Hochrein, H., Vremec, D., Scott, B., Hertzog, P., Tatarczuch, L., \& Shortman, K. (2003). Dendritic cell precursor populations of mouse blood: identification of the murine homologues of human blood plasmacytoid pre-DC2 and CD11c+ DC1 precursors. Blood. 101: 1453-1459.

Pepose, J.S. (1991). Herpes simplex keratitis: role of viral infection versus immune response. Surv Ophthalmol. 35: 345-352.

Pepose, J.S., Gardner, K.M., Nestor, M.S., Foos, R.Y., \& Pettit, T.H. (1985). Detection of HLA class I and II antigens in rejected human corneal allografts. Ophthalmology. 92: 14801484 .

Pflugfelder, S.C. (1998). Advances in the diagnosis and management of keratoconjunctivitis sicca. Curr Opin Ophthalmol. 9: 50-53.

Redfern, R.L. \& McDermott, A.M. (2010). Toll-like receptors in ocular surface disease. Exp Eye Res. 90: 679-687.

Russell, R.G., Nasisse, M.P., Larsen, H.S., \& Rouse, B.T. (1984). Role of T-lymphocytes in the pathogenesis of herpetic stromal keratitis. Invest Ophthalmol Vis Sci. 25: 938-944.

Sankaridurg, P.R., Rao, G.N., Rao, H.N., Sweeney, D.F., \& Holden, B.A. (2000). ATPasepositive dendritic cells in the limbal and corneal epithelium of guinea pigs after extended wear of hydrogel lenses. Cornea. 19: 374-377.

Schang, L.M., Phillips, J., \& Schaffer, P.A. (1998). Requirement for cellular cyclin-dependent kinases in herpes simplex virus replication and transcription. J Virol. 72: 5626-5637.

Schang, L.M., Rosenberg, A., \& Schaffer, P.A. (2000). Roscovitine, a specific inhibitor of cellular cyclin-dependent kinases, inhibits herpes simplex virus DNA synthesis in the presence of viral early proteins. J Virol. 74: 2107-2120.

Schaumberg, D.A., Sullivan, D.A., Buring, J.E., \& Dana, M.R. (2003). Prevalence of dry eye syndrome among US women. Am J Ophthalmol. 136: 318-326.

Shukla, D., Liu, J., Blaiklock, P., Shworak, N.W., Bai, X., Esko, J.D., Cohen, G.H., Eisenberg, R.J., Rosenberg, R.D., \& Spear, P.G. (1999). A novel role for 3-O-sulfated heparan sulfate in herpes simplex virus 1 entry. Cell. 99: 13-22.

Shukla, D. \& Spear, P.G. (2001). Herpesviruses and heparan sulfate: an intimate relationship in aid of viral entry. J Clin Invest. 108: 503-510.

Smith, P.M., Wolcott, R.M., Chervenak, R., \& Jennings, S.R. (1994). Control of acute cutaneous herpes simplex virus infection: $T$ cell-mediated viral clearance is dependent upon interferon-gamma (IFN-gamma). Virology. 202: 76-88. 
Spear, P.G. (2004). Herpes simplex virus: receptors and ligands for cell entry. Cell Microbiol. 6: 401-410.

Stern, M.E., Beuerman, R.W., Fox, R.I., Gao, J., Mircheff, A.K., \& Pflugfelder, S.C. (1998). The pathology of dry eye: the interaction between the ocular surface and lacrimal glands. Cornea. 17: 584-589.

Stern, M.E., Gao, J., Siemasko, K.F., Beuerman, R.W., \& Pflugfelder, S.C. (2004). The role of the lacrimal functional unit in the pathophysiology of dry eye. Exp Eye Res. 78: 409416.

Stewart GL, Kim I, Shupe K, Alizadeh, H. Silvany, R. McCulley, J. P. Niederkorn, J. Y. (1992) Chemotactic response of macrophages to Acanthamoeba castellanii antigen and antibody-dependent macrophage-mediated killing of the parasite. J Parasitol. ;78:849-855.

Streilein, J.W. (1993). Tissue barriers, immunosuppressive microenvironments, and privileged sites: the eye's point of view. Reg Immunol. 5: 253-268.

Streilein, J.W. (1995). Immunological non-responsiveness and acquisition of tolerance in relation to immune privilege in the eye. Eye (Lond). 9 ( $\mathrm{Pt} 2$ ): 236-240.

Streilein, J.W. (1999). Immunobiology and immunopathology of corneal transplantation. Chem Immunol. 73: 186-206.

Streilein, J.W., Bradley, D., Sano, Y., \& Sonoda, Y. (1996). Immunosuppressive properties of tissues obtained from eyes with experimentally manipulated corneas. Invest Ophthalmol Vis Sci. 37: 413-424.

Streilein, J.W., Dana, M.R., \& Ksander, B.R. (1997). Immunity causing blindness: five different paths to herpes stromal keratitis. Immunol Today. 18: 443-449.

Streilein, J.W., Toews, G.B., \& Bergstresser, P.R. (1979). Corneal allografts fail to express Ia antigens. Nature. 282: 326-327.

Stuart, P.M., Griffith, T.S., Usui, N., Pepose, J., Yu, X., \& Ferguson, T.A. (1997). CD95 ligand (FasL)-induced apoptosis is necessary for corneal allograft survival. J Clin Invest. 99: 396-402.

Sun, Y., Chandra, J., Mukherjee, P., Szczotka-Flynn, L., Ghannoum, M.A., \& Pearlman, E. (2010). A murine model of contact lens-associated fusarium keratitis. Invest Ophthalmol Vis Sci. 51: 1511-1516.

Sun, Y., Karmakar, M., Roy, S., Ramadan, R.T., Williams, S.R., Howell, S., Shive, C.L., Han, Y., Stopford, C.M., Rietsch, A., \& Pearlman, E. TLR4 and TLR5 on corneal macrophages regulate Pseudomonas aeruginosa keratitis by signaling through MyD88-dependent and -independent pathways. J Immunol. 185: 4272-4283.

Tang, Q. \& Bluestone, J.A. (2008). The Foxp3+ regulatory T cell: a jack of all trades, master of regulation. Nat Immunol. 9: 239-244.

Tarabishy, A.B., Aldabagh, B., Sun, Y., Imamura, Y., Mukherjee, P.K., Lass, J.H., Ghannoum, M.A., \& Pearlman, E. (2008). MyD88 regulation of Fusarium keratitis is dependent on TLR4 and IL-1R1 but not TLR2. J Immunol. 181: 593-600.

Thiel, M.A., Kaufmann, C., Coster, D.J., \& Williams, K.A. (2009). Antibody-based immunosuppressive agents for corneal transplantation. Eye (Lond). 23: 1962-1965.

Thomas, J., Gangappa, S., Kanangat, S., \& Rouse, B.T. (1997). On the essential involvement of neutrophils in the immunopathologic disease: herpetic stromal keratitis. $J$ Immunol. 158: 1383-1391. 
Thomas, J., Kanangat, S., \& Rouse, B.T. (1998). Herpes simplex virus replication-induced expression of chemokines and proinflammatory cytokines in the eye: implications in herpetic stromal keratitis. J Interferon Cytokine Res. 18: 681-690.

Thomas, J. \& Rouse, B.T. (1997). Immunopathogenesis of herpetic ocular disease. Immunol Res. 16: 375-386.

Thomas, P.A. \& Geraldine, P. (2007). Infectious keratitis. Curr Opin Infect Dis. 20: 129-141.

Torres, P.F. \& Kijlstra, A. (2001). The role of cytokines in corneal immunopathology. Ocul Immunol Inflamm. 9: 9-24.

Traver, D., Akashi, K., Manz, M., Merad, M., Miyamoto, T., Engleman, E.G., \& Weissman, I.L. (2000). Development of CD8alpha-positive dendritic cells from a common myeloid progenitor. Science. 290: 2152-2154.

Trinkaus-Randall, V., Leibowitz, H.M., Ryan, W.J., \& Kupferman, A. (1991). Quantification of stromal destruction in the inflamed cornea. Invest Ophthalmol Vis Sci. 32: 603-609.

Tullo, A.B., Shimeld, C., Blyth, W.A., Hill, T.J., \& Easty, D.L. (1983). Ocular infection with herpes simplex virus in nonimmune and immune mice. Arch Ophthalmol. 101: 961964.

Tumpey, T.M., Chen, S.H., Oakes, J.E., \& Lausch, R.N. (1996). Neutrophil-mediated suppression of virus replication after herpes simplex virus type 1 infection of the murine cornea. J Virol. 70: 898-904.

Tumpey, T.M., Cheng, H., Cook, D.N., Smithies, O., Oakes, J.E., \& Lausch, R.N. (1998). Absence of macrophage inflammatory protein-1alpha prevents the development of blinding herpes stromal keratitis. J Virol. 72: 3705-3710.

Van Horn, D.L., Davis, S.D., Hyndiuk, R.A., \& Alpren, T.V. (1978). Pathogenesis of experimental Pseudomonas keratitis in the guinea pig: bacteriologic, clinical, and microscopic observations. Invest Ophthalmol Vis Sci. 17: 1076-1086.

Van Klink F, Taylor WM, Alizadeh H, Jager MJ, van Rooijen N, Niederkorn JY. (1996) The role of macrophages in Acanthamoeba keratitis. Invest Ophthalmol Vis Sci. 37:12711281.

Verjans, G.M., Remeijer, L., Mooy, C.M., \& Osterhaus, A.D. (2000). Herpes simplex virusspecific $\mathrm{T}$ cells infiltrate the cornea of patients with herpetic stromal keratitis: no evidence for autoreactive T cells. Invest Ophthalmol Vis Sci. 41: 2607-2612.

Weiss, S.J. (1989). Tissue destruction by neutrophils. N Engl J Med. 320: 365-376.

Whitley, R.J. \& Roizman, B. (2001). Herpes simplex virus infections. Lancet. 357: 1513-1518.

Wolpe, S.D., Davatelis, G., Sherry, B., Beutler, B., Hesse, D.G., Nguyen, H.T., Moldawer, L.L., Nathan, C.F., Lowry, S.F., \& Cerami, A. (1988). Macrophages secrete a novel heparin-binding protein with inflammatory and neutrophil chemokinetic properties. J Exp Med. 167: 570-581.

Wolpe, S.D., Sherry, B., Juers, D., Davatelis, G., Yurt, R.W., \& Cerami, A. (1989). Identification and characterization of macrophage inflammatory protein 2. Proc Natl Acad Sci U S A. 86: 612-616.

WorkShop, I.D.E. (2007a). The definition and classification of dry eye disease: report of the Definition and Classification Subcommittee of the International Dry Eye WorkShop (2007). Ocul Surf. 5: 75-92.

WorkShop, I.D.E. (2007b). The epidemiology of dry eye disease: report of the Epidemiology Subcommittee of the International Dry Eye WorkShop (2007). Ocul Surf. 5: 93-107. 
Wu, L., D'Amico, A., Hochrein, H., O'Keeffe, M., Shortman, K., \& Lucas, K. (2001). Development of thymic and splenic dendritic cell populations from different hemopoietic precursors. Blood. 98: 3376-3382.

Wuest, T.R. \& Carr, D.J. (2008). Dysregulation of CXCR3 signaling due to CXCL10 deficiency impairs the antiviral response to herpes simplex virus 1 infection. $J$ Immunol. 181: 7985-7993.

Yamagami, S., Hamrah, P., Zhang, Q., Liu, Y., Huq, S., \& Dana, M.R. (2005). Early ocular chemokine gene expression and leukocyte infiltration after high-risk corneal transplantation. Mol Vis. 11: 632-640.

Yamagami, S., Isobe, M., \& Tsuru, T. (2000). Characterization of cytokine profiles in corneal allograft with anti-adhesion therapy. Transplantation. 69: 1655-1659.

Yamagami, S., Miyazaki, D., Ono, S.J., \& Dana, M.R. (1999). Differential chemokine gene expression in corneal transplant rejection. Invest Ophthalmol Vis Sci. 40: 2892-2897.

Yildiz, E.H., Abdalla, Y.F., Elsahn, A.F., Rapuano, C.J., Hammersmith, K.M., Laibson, P.R., \& Cohen, E.J. (2010). Update on fungal keratitis from 1999 to 2008. Cornea. 29: 14061411.

Youker, K., Smith, C.W., Anderson, D.C., Miller, D., Michael, L.H., Rossen, R.D., \& Entman, M.L. (1992). Neutrophil adherence to isolated adult cardiac myocytes. Induction by cardiac lymph collected during ischemia and reperfusion. J Clin Invest. 89: 602-609.

Yuan, X. \& Wilhelmus, K.R. (2009). Corneal neovascularization during experimental fungal keratitis. Mol Vis. 15: 1988-1996.

Zhao, Z.S., Granucci, F., Yeh, L., Schaffer, P.A., \& Cantor, H. (1998). Molecular mimicry by herpes simplex virus-type 1: autoimmune disease after viral infection. Science. 279: 1344-1347.

Zheng, M., Deshpande, S., Lee, S., Ferrara, N., \& Rouse, B.T. (2001). Contribution of vascular endothelial growth factor in the neovascularization process during the pathogenesis of herpetic stromal keratitis. J Virol. 75: 9828-9835.

Zheng, X., de Paiva, C.S., Li, D.Q., Farley, W.J., \& Pflugfelder, S.C. Desiccating stress promotion of Th17 differentiation by ocular surface tissues through a dendritic cellmediated pathway. Invest Ophthalmol Vis Sci. 51: 3083-3091.

Zhou, Z., Wu, M., Barrett, R.P., McClellan, S.A., Zhang, Y., \& Hazlett, L.D. (2010). Role of the Fas pathway in Pseudomonas aeruginosa keratitis. Invest Ophthalmol Vis Sci. 51: 2537-2547.

Zhu, S., Dekaris, I., Duncker, G., \& Dana, M.R. (1999). Early expression of proinflammatory cytokines interleukin-1 and tumor necrosis factor-alpha after corneal transplantation. J Interferon Cytokine Res. 19: 661-669.

Zhu, S.N. \& Dana, M.R. (1999). Expression of cell adhesion molecules on limbal and neovascular endothelium in corneal inflammatory neovascularization. Invest Ophthalmol Vis Sci. 40: 1427-1434. 


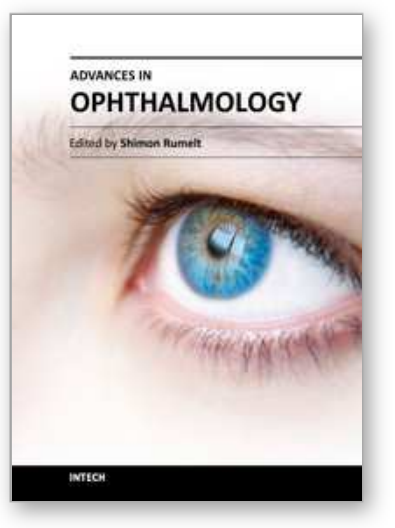

\author{
Advances in Ophthalmology \\ Edited by Dr Shimon Rumelt
}

ISBN 978-953-51-0248-9

Hard cover, 568 pages

Publisher InTech

Published online 07, March, 2012

Published in print edition March, 2012

This book focuses on the different aspects of ophthalmology - the medical science of diagnosis and treatment of eye disorders. Ophthalmology is divided into various clinical subspecialties, such as cornea, cataract, glaucoma, uveitis, retina, neuro-ophthalmology, pediatric ophthalmology, oncology, pathology, and oculoplastics. This book incorporates new developments as well as future perspectives in ophthalmology and is a balanced product between covering a wide range of diseases and expedited publication. It is intended to be the appetizer for other books to follow. Ophthalmologists, researchers, specialists, trainees, and general practitioners with an interest in ophthalmology will find this book interesting and useful.

\title{
How to reference
}

In order to correctly reference this scholarly work, feel free to copy and paste the following:

Yureeda Qazi, Aslihan Turhan and Pedram Hamrah (2012). Trafficking of Immune Cells in the Cornea and Ocular Surface, Advances in Ophthalmology, Dr Shimon Rumelt (Ed.), ISBN: 978-953-51-0248-9, InTech, Available from: http://www.intechopen.com/books/advances-in-ophthalmology/trafficking-of-immune-cells-inthe-cornea-and-ocular-surface

\section{INTECH}

open science | open minds

\section{InTech Europe}

University Campus STeP Ri Slavka Krautzeka 83/A 51000 Rijeka, Croatia

Phone: +385 (51) 770447

Fax: +385 (51) 686166 www.intechopen.com

\section{InTech China}

Unit 405, Office Block, Hotel Equatorial Shanghai No.65, Yan An Road (West), Shanghai, 200040, China 中国上海市延安西路65号上海国际贵都大饭店办公楼405单元 Phone: +86-21-62489820

Fax: +86-21-62489821 
(C) 2012 The Author(s). Licensee IntechOpen. This is an open access article distributed under the terms of the Creative Commons Attribution 3.0 License, which permits unrestricted use, distribution, and reproduction in any medium, provided the original work is properly cited. 